the loan of some apparatus. We wish to thank the directors of Lever Brothers and Unilever Ltd. for permission to publish these results.

V. VAND

T. R. LOMER

A. LANG

Research Department,

Lever Brothers and Unilever Ltd.,

Port Sunlight, Cheshire.

Feb. 11.

${ }^{1}$ Buerger, Smith, Ryer and Spike, Proc. U.S. Nat. Acad. Sci., 31, 226 (1945).

${ }^{2}$ Piper, J. Chem. Soc., 234 (1929).

\section{Molecular Sieve Action at Low Temperatures}

BY using crystalline network lattices with uniform interstices as sorbents, it has proved possible to carry out a great many resolutions of molecular mixtures ${ }^{1}$. Molecules which are of the right dimensions to enter and occupy the intra-crystalline interstices are then removed by selective sorption, leaving behind molecules which are too large or have the wrong shape, and hence toward which the network lattice is a non-sorbent. Crystalline parameters define with precision the dimensions of the interstices (which are linked to give channels); and, therefore, the molecular sieve action is equally clearly defined. As a result separations become quantitative in numerous instances (for example, $n$-paraffins from iso-paraffins using dehydrated chabazite as sorbent).

Between these two extremes lies a transition group of molecules which work their way slowly into the crystal by a process of activated diffusion ${ }^{1}$. Indeed, there is a complete range of velocities of sorption between the extremes. Some molecules are sorbed rapidly at room temperatures, but more slowly at $-78^{\circ} \mathrm{C}$. (for example, argon and nitrogen in calcium and barium mordenites). Then one finds a very low energy of activation for diffusion ${ }^{2}$. (This energy of activation is not due to chemical forces, but is a reflexion of the periodic potential energy field in the crystal encountered by the molecule as it moves from one site of maximum sorption potential to the next.)

It has now been found that the molecular sieve behaviour can be extended considerably by sorbing those gases with a small energy of activation for diffusion at still lower temperatures $\left(-183^{\circ}\right.$ to $-195^{\circ} \mathrm{C}$.). In this way, for example, using a suitable molecular sieve sorbent, great differences in the sorption-rates of oxygen, nitrogen and argon were found, which seem quite sufficient to permit quantitative or semiquantitative resolutions of their mixtures. The sorption-rates at $-184^{\circ} \mathrm{C}$. were as expected in the order oxygen $>$ nitrogen $>$ argon, in the inverse relation to the dimension important for diffusion down a narrow interstitial channel, namely, the crosssectional diameter normal to the molecular axis in oxygen and nitrogen molecules, and the diameter of the argon atom respectively ${ }^{1,2}$.

As an illustration, the accompanying graph shows the relative amounts of argon, nitrogen and oxygen sorbed by $1 \mathrm{gm}$. of dehydrated levynite at $-184^{\circ} \mathrm{C}$. at various times. Apart from a small and rapid sorption on external surfaces of the crystal powder, argon is sorbed at a very slow rate. Moreover, if a mixture of argon and oxygen were passed through the powder at $-184^{\circ}$, by adjusting the time of contact to one or two minutes, one would here expect a 99 per cent removal of oxygen from the mixture.

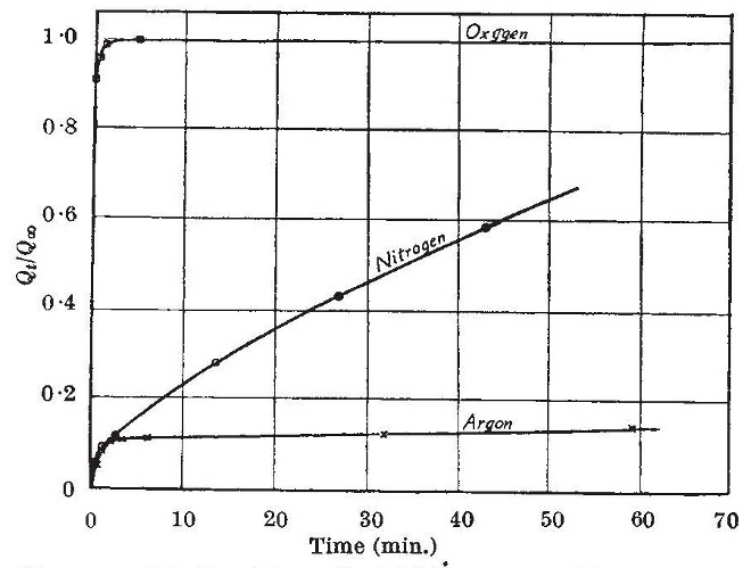

WIDELY DIVKRGENT SORPTION-RATES IN DFHYDRATED LEVYNITF AT $-184^{\circ} \mathrm{C}$, , DUE TO THE MOLECUL,AR SIEVE ACTIVITY OF THE
ZEOLITE

$Q_{t}$ denotes c.c. sorbed at N.T.P./gm.

$Q_{\infty}$ denotes sorption at equilibrium in c.c. at N.T.P./gm.; oxygen, 10.02 c.c./gm.; nitrogen, 9.77 c.c./gm.; argon, 10.13 c.c./gm.

Such contact times would also give a good separation of nitrogen from oxygen. These results, particularly on argon-oxygen mixtures, should be of interest to the argon industry, and the liquid air industry. The experiments also demonstrate for the first time that levynite, like chabazite ${ }^{3}$, gmelinite ${ }^{2}$, mordenite ${ }^{2}$ and certain synthetic zeolites ${ }^{4}$, has molecular sieve activity.

A full account of these and other results will be published elsewhere.

\section{Chemistry Department,}

R. M. BARRER

$$
\begin{aligned}
& \text { Bedford College, } \\
& \text { London, N.W.1. } \\
& \text { Jan. } 31 .
\end{aligned}
$$

${ }^{1}$ Barrer, J. Soc. Chem. Ind., 44, 130 (1945).

"Barrer, Trans. Farad. Soc., 40, 555 (1944). Ann. Rep., 41, 42, Table III (1944).

${ }^{3}$ Barrer and Ibbitson. Trans. Farad. Soc., 40, 195 and 206 (1944).

4 Barrer and Riley, in the press.

\section{Structures of Ethylene Oxide and Cyclopropane}

IT has recently been suggested by $\mathrm{Walsh}^{1}$ that the structures I and II represent the properties of ethylene oxide and cyclopropane better than do the classical formulæ III and IV. In these new structures the oxygen atom in $\mathrm{I}$, and the $\mathrm{CH}_{2}$ group in II, are attached to the double bond by a dative link formed from the $\pi$-electron pair of the 'ethylene' portion of the molecule. These ideas were apparently put forward because Zimakov ${ }^{2}$ has lately pointed out that the classical Würtz formula for ethylene oxide does not adequately account for its high reactivity; also because formula IV gives no indication of the characteristic reactivity of cyclopropane.

$$
\begin{array}{cccc}
\mathrm{CH}_{2}=\mathrm{CH}_{2} & \mathrm{CH}_{2}=\mathrm{CH}_{2} & \mathrm{CH}_{2}-\mathrm{CH}_{2} & \mathrm{CH}_{2}-\mathrm{CH}_{2} \\
\downarrow & \mathrm{CH}_{2} & 0 & \mathrm{CH}_{2} \\
\text { I } & \text { II } & \text { III } & \text { IV }
\end{array}
$$

The conception of $\pi$-electron dative bonds is due originally to Dewar ${ }^{3}$, and though it does help to explain certain molecular rearrangements, its use in the suggested structures makes it difficult to reconcile these with the known Raman and infra-red spectra 